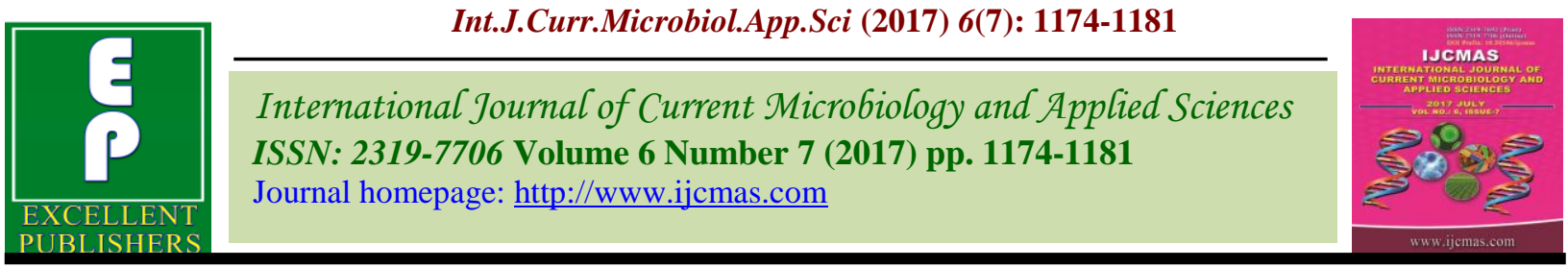

Original Research Article

https://doi.org/10.20546/ijcmas.2017.607.142

\title{
Microbial Degradation of Aromatic hydrocarbon: Naphthalene through Nocardiopsis alba RD3
}

\author{
Ruby Doley ${ }^{1}$, Manoj Barthakur ${ }^{1 *}$ and Bijoy S. Goswami ${ }^{2}$ \\ ${ }^{1}$ Department of Botany, B.Borooah College, Guwahati, India \\ ${ }^{2}$ Department of Chemistry, B.Borooah College, Guwahati, India \\ *Corresponding author
}

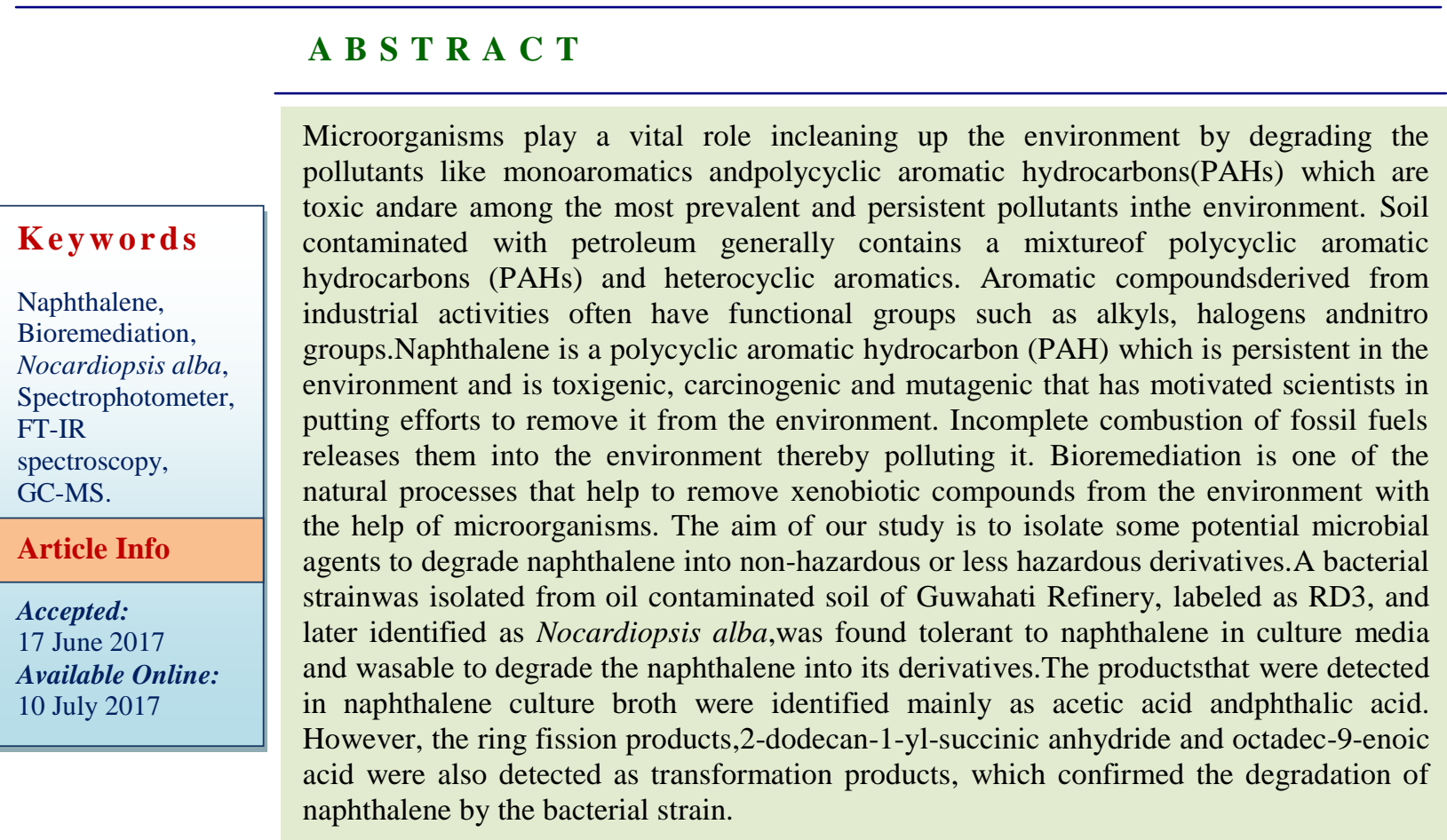

\section{Introduction}

Polycyclic aromatic hydrocarbons (PAHs) contain two or more benzene rings in their structure, which are hydrophobic and have lower solubility than the mono aromatics. PAHs are generally contaminating the environment as a result of oil refinery discharge, accidental oil spill or weathering of creosote-impregnated pylons (Coates, 2004). Naphthalene is an organic compound with chemical formulaC $\mathrm{C}_{10} \mathrm{H}_{8}$. It is the simplest polycyclic aromatic hydrocarbon, and is a white crystalline solid with a characteristic odour that is detectable at concentrations as low as $0.08 \mathrm{ppm}$ by mass. As an aromatic hydrocarbon, naphthalene structure consists of a fused pair of benzene rings. It is best known as the main ingredient of traditional mothballs. Naphthalene is the most abundant single component of coal tar. Although the composition of coal tar varies with the coal from which it is produced, typical coal tar is about $10 \%$ naphthalene by weight. In industrial practice, distillation of coal tar yields oil containing about 50\% naphthalene, 
along with twelve other aromatic compounds. Naphthalene is one of the 16 PAHs classified as priority pollutant by US environmental Protection agency (USEPA, 1994, 2004). Exposure to large amounts of naphthalene may damage or destroy red blood cells, most commonly in people with an underlying G6PD (glucose-6-phosphate dehydrogenase) deficiency.

It is well known that microorganisms can degrade environmental pollutants. The continuous search for ways of cleaning up the environment has revealed a diverse range of microorganisms that can utilize these compounds as substrates and thereby convert them into less toxic products. It is well known that microorganisms play the central role in nutrient cycling and at one time, their vast enzymatic capacity was considered to be infallible (Alexander, 1999). Use of microorganisms to degrade environmental pollutants which is called bioremediation is one of the important ways to remove environmental contamination. Bioremediation is generally considered a safe and less expensive method for the removal of hazardous contaminants and production of non-toxic by-products (Ward et al., 2003). Bioremediation process involves detoxification and mineralization, where the waste is converted into inorganic compounds such as carbon dioxide, water and methane (Varsha et al., 2011). A number of authors have reported the degradation of naphthalene through application of different microbial agents. Mittal and Singh (2009) measured the microbial degradation value of polycyclic aromatic hydrocarbon like Naphthalene through Gas Chromatography. Kafilzadeh et al., (2011) isolated 5 bacterial species belong to Staphylococcus sp. Corynebacterium sp. Pseudomonas sp. Bacillus sp. And Micrococcus sp. and reported that all these strains were significantly able to degrade naphthalene. Pawar et al., (2013) characterized Gram positive and Gram negative bacteria belonging to genus Micrococcus sp, Bacillus sp, Staphylococcus sp and Pseudomonas sp isolated from marine and petroleum soil samples which showed degradation of naphthalene. A review on Microorganism as a tool for bioremediation technology using designed and developed laboratory Bioreactors for cleaning environment was conducted by Singh et al., (2014).

In this study we used naphthalene, which is an aromatic polycyclic hydrocarbon and considered among the 16 PAHs classified as priority pollutants by USEPA. A bacterial strain was isolated from oil contaminated soil of Guwahati Refinery, Assam and identified as Nocardiopsis alba. Here, the process of degradation of naphthalene by our isolate has been studied and also the transformation products were identified by GC-MS.

\section{Materials and Methods}

\section{Isolation and identification of bacterial strain}

The oil contaminated soil sample was collected from Guwahati Oil Refinery, Assam, India. The soil sample was collected in sterile polythene bag and brought to the laboratory for microbial isolation. The stock solution was prepared by mixing $1 \mathrm{gm}$ of soil in $100 \mathrm{ml}$ sterile distilled water and serially diluted. Dilutions below $10^{-6}$ were inoculated into nutrient broth ( $\mathrm{pH} \mathrm{7.4)} \mathrm{and} \mathrm{incubated} \mathrm{at}$ $37^{\circ} \mathrm{C}$ for 7 days (Singh and Pandey, 2013). Characterization and identification of the bacteria was done by biochemical tests and16s rDNA sequence analysis through homology sequence and phylogenetic analysis.

DNA was extracted from the culture and its quality was evaluated on $1.0 \%$ agarose gel. 
Fragment of $16 \mathrm{~S}$ rDNA gene was amplified by $27 \mathrm{~F}$ and $1492 \mathrm{R}$ primers. A single discrete PCR amplicon band of $1500 \mathrm{bp}$ was observed when resolved on agarose gel. The PCR amplicon was purified to remove contaminants. 16srDNA sequencing was carried out by Eurofin Genomic, Bangalore, India.

The sequence obtained was compared with the nucleotide sequences of NCBI by using BLAST algorithm. Based on maximum identity score first ten sequences were selected and aligned using multiple alignment software programs. Clustal W. Distance matrix was generated using RDP database and the phylogenetic tree was constructed using MEGA 4.

\section{Determination of growth at different concentration of naphthalene}

Biodegradation ability of the isolated strain was studied using $100 \mathrm{ppm}$ concentration of naphthalene in $100 \mathrm{ml}$ nutrient broth and incubated at $37^{\circ} \mathrm{C}$. Within interval of 24 hours, $5 \mathrm{ml}$ sample were collected periodically from the flask and the OD measured at $600 \mathrm{~nm}$ in UV spectrophotometer.

\section{Determination of naphthalene degradation of isolate}

Naphthalene degrading ability of the isolate was monitored by spectrophotometric method as used by Pawer et al., (2013). $1 \mathrm{ml}$ suspension of the isolate was inoculated in $100 \mathrm{ml}$ nutrient broth containing $80 \mathrm{ppm}$ and $100 \mathrm{ppm}$ of naphthalene as the sole source of carbon.

Culture broth was incubated at $37^{\circ} \mathrm{C}$ and naphthalene degradation ability of the isolate was monitored periodically at 24 hours intervals through UV spectrophotometer by taking the absorbance at $365 \mathrm{~nm}$.

\section{Sample preparation for FT-IR and GC-MS} Analysis

To examine the naphthalene degradation, the bacterial strain was inoculated in nutrient broth supplemented with $80 \mathrm{ppm}$ and 100 ppm naphthalene respectively and incubated at $37^{\circ} \mathrm{C}$. After 9 days of incubation the culture broths were centrifuged separately at $15000 \mathrm{rpm}$. The supernatant were extracted in $50 \mathrm{ml} \mathrm{n}$-hexane each and filtered through Whatman No. 42 filter paper. The filtrate was dried under vacuum. The residues thus obtained were dissolved in $3 \mathrm{ml}$-hexane and used for FT-IR and GC-MS analysis. FT-IR spectra were recorded using $\mathrm{KBr}$ pellets in order to confirm the intermediate metabolites.

\section{Results and Discussion}

\section{Isolation of bacteria}

A total of 13 bacterial strains were isolated from the soil sample, however the strain designated as RD3 was found best for tolerance of naphthalene in culture broth (data not shown) and thus it was considered for further experiments.

\section{Bacterial identification by $16 S$ rDNA analysis}

Fragment of $16 \mathrm{~S}$ rDNA gene was amplified by $27 \mathrm{~F}$ and $1492 \mathrm{R}$ primers. PCR amplification of the $16 \mathrm{~S}$ rDNA gene produced fragments of approximately 1500 base pairs in size (Fig. 1). Forward and reverse DNA sequencing reaction of PCR amplicon was carried out with forward primer and reverse primers using BDT v3.1 Cycle sequencing kit on ABI 3730xl Genetic Analyzer. The 16S rDNA gene sequence was used to carry out BLAST with the database of NCBI gene bank database. Based on maximum identity score first ten sequences were selected and aligned using multiple alignment software programs 
Clustal W. Distance matrix was generated using RDP database and the phylogenetic tree was constructed using MEGA 4. Identification of the strains by $16 \mathrm{~S}$ rDNA gene sequence analysis revealed that the strain shows $100 \%$ similarity with Nocardiopsis alba. Therefore the isolated bacterial strain has been identified as Nocardiopsis alba strain.

Distance matrix was generated using RDP database and the phylogenetic tree was constructed using MEGA 4. Identification of the strains by $16 \mathrm{~S}$ rDNA gene sequence analysis revealed that the strain shows $100 \%$ similarity with Nocardiopsis alba. Therefore the isolated bacterial strain has been identified as Nocardiopsis alba strain.

\section{Naphthalene degradation by Nocardiopsis alba strain}

The bacterial strain Nocardiopsis alba RD3 grows in the culture broth utilizing naphthalene as the sole source of carbon and energy. Bacterial growth after the lag phase (Fig. 1) increases exponentially indicating that naphthalene has been utilized for cell growth. Residual naphthalene in the culture broth decrease simultaneously from $72 \mathrm{hrs}$ onwards along with the cell growth (Fig. 2). Thus there is a correlation between the cell growth of the bacteria and degradation of naphthalene. The bacteria utilize naphthalene as carbon source rapidly in the exponential growth phase and thereby the concentration is depleted in the culture broth.

FTIR spectrum of hexane extract of culture broth supplemented with 60ppm (Fig. 3) naphthalene exhibited the characteristic peaks at $2984 \mathrm{~cm}^{-1}$ and $2834 \mathrm{~cm}^{-1}$ indicating the presence of $-\mathrm{CH}_{3}$ and $-\mathrm{CH}_{2}$ in aliphatic antisym and sym, peak at $2724 \mathrm{~cm}^{-1}$ suggested the presence of carboxylic acid $\mathrm{O}-\mathrm{H}$ stretching, whereas the peaks at $1452 \mathrm{~cm}^{-1}$ and $1373 \mathrm{~cm}^{-1}$ showing $-\mathrm{CH}$ bending and peak at $1145 \mathrm{~cm}^{-1}$ suggested the presence of alkylated benzene in the extract. Similarly, $100 \mathrm{ppm}$ (Fig. 4) naphthalene culture broth also showed characteristic peaks of carboxylic acid and C-O groups at around $2727 \mathrm{~cm}^{-1}$ and $1379 \mathrm{~cm}^{-1}$ respectively. The absence of such peaks at these regions in the control hexane extract supplemented with 60 and $100 \mathrm{ppm}$ naphthalene (without inoculation of bacteria) reveals the degradation of naphthalene by the bacterial strain (Figs. 3 and 4).
Fig.1 gDNA 16s PCR amplicon

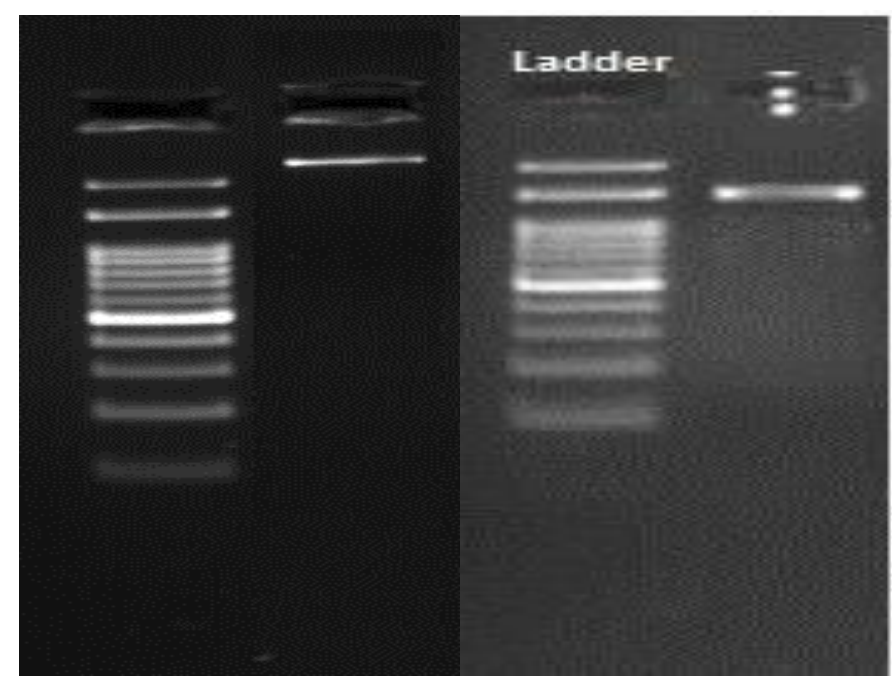


Fig.2 Phylogenetic tree of Nocardiopsis alba

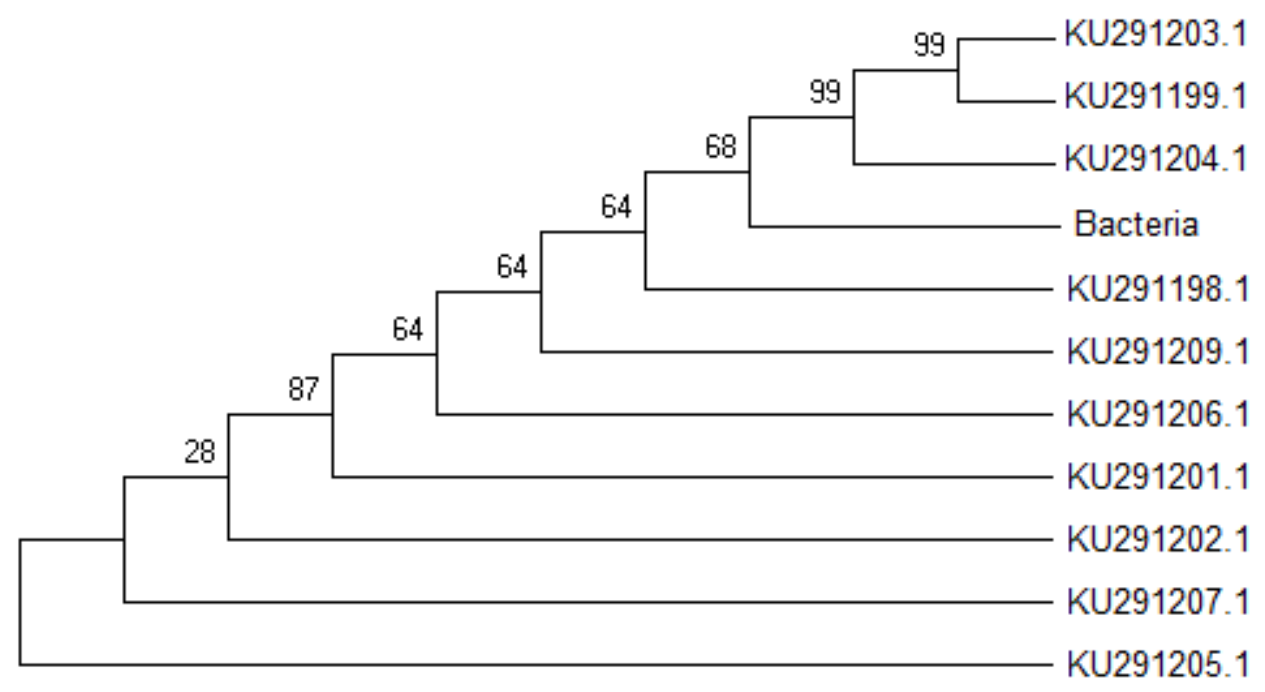

Fig.3 Growth of Nocardiopsis alba (in 100 ppm naphthalene broth) against time of incubation

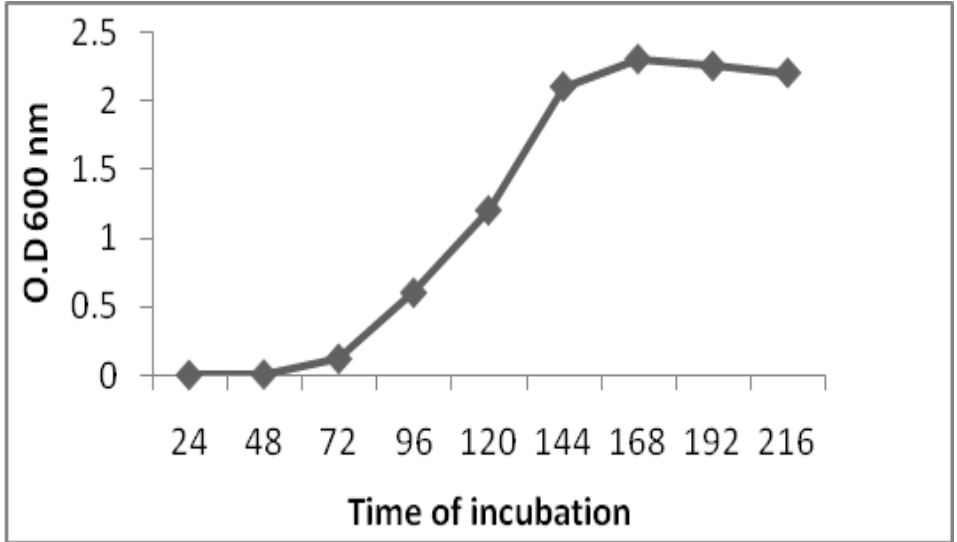

Fig.4 Growth of Nocardiopsis alba (in 100 ppm naphthalene broth) against time of incubation

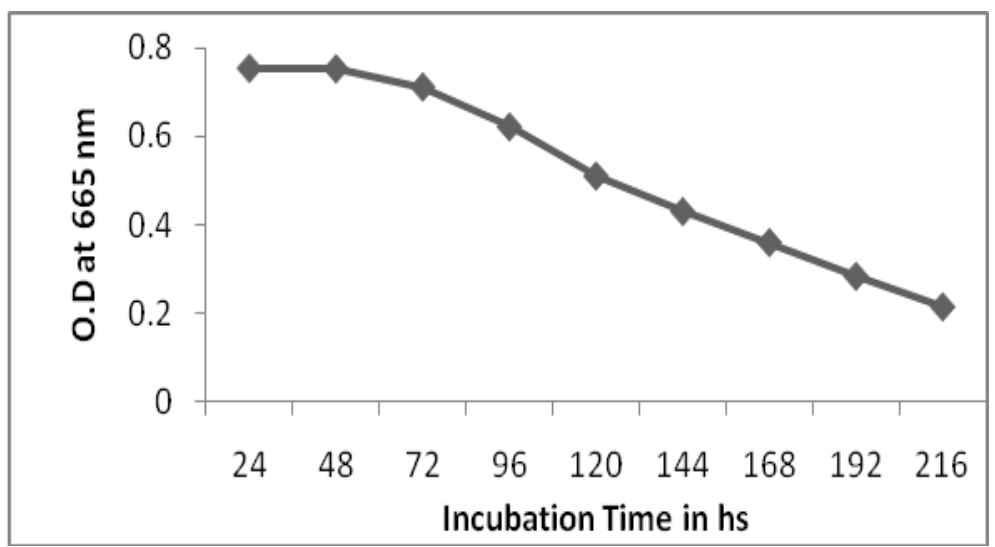


Fig.5 FT-IR of 60 ppm Naphthalene

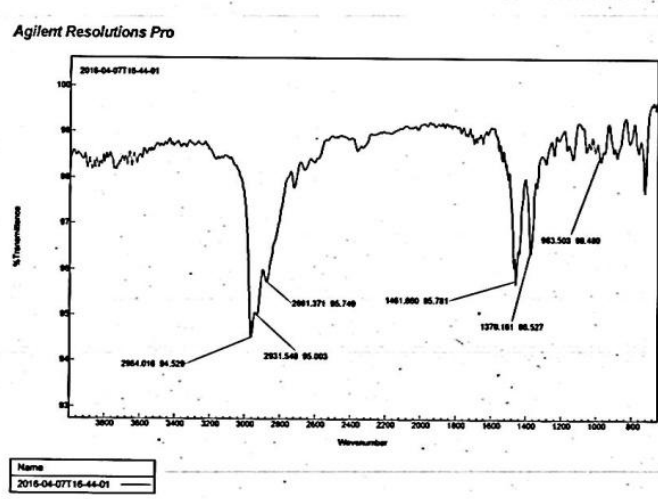

Control

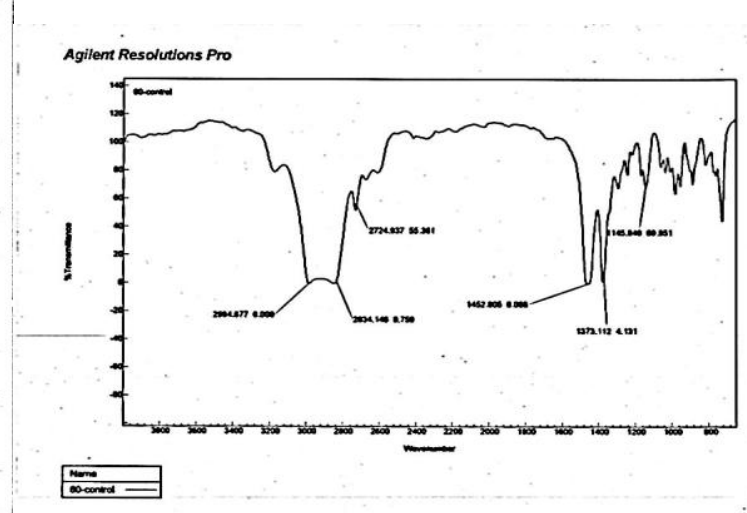

Treated

Fig.6 FT-IR of 100 ppm naphthalene degradation

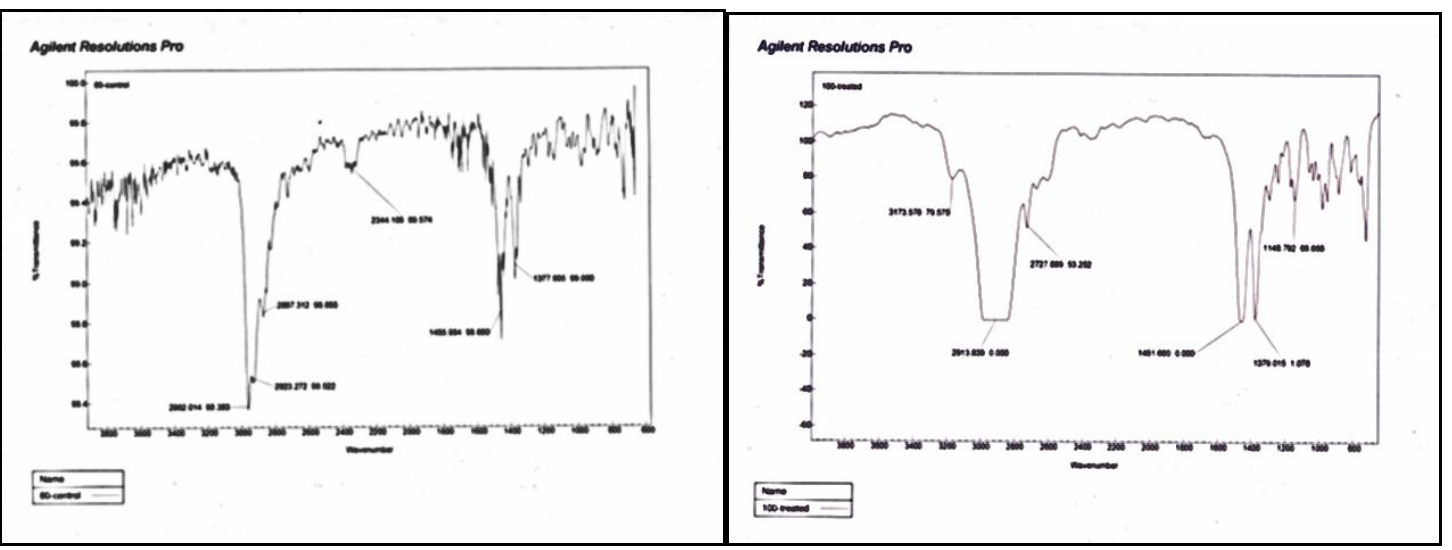

Control

Treated

Fig.7 GC-MS spectrum of degraded naphthalene of 100 ppm broth culture

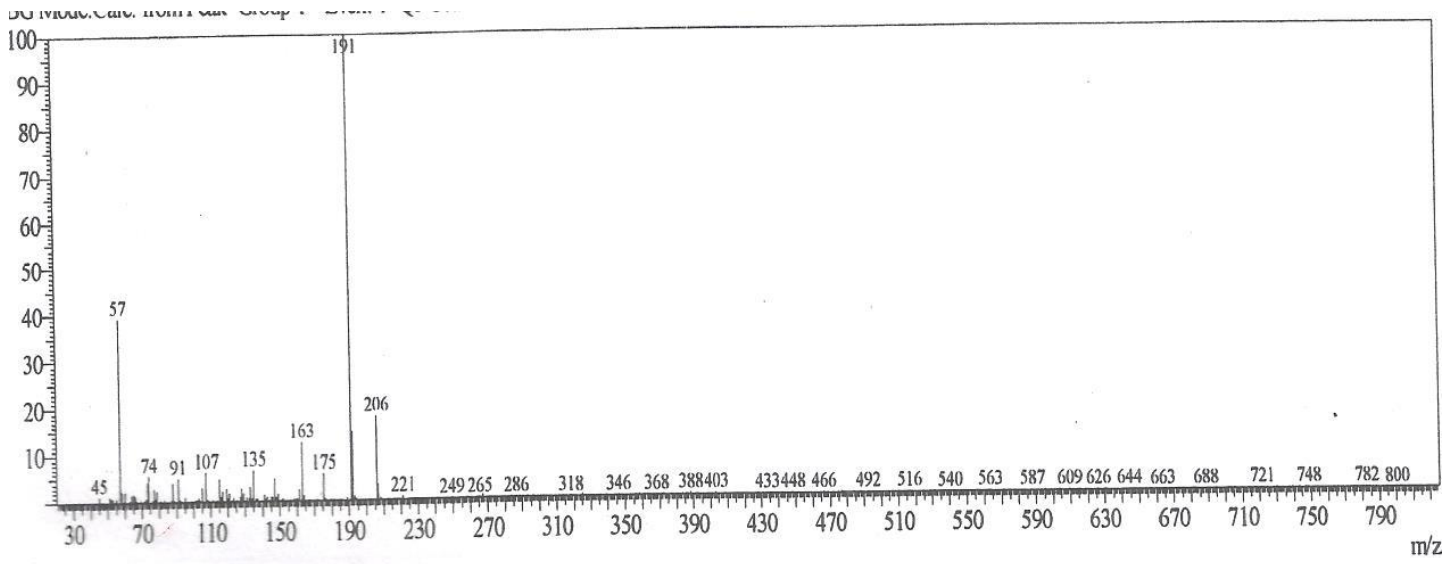


Catabolism of alkyl polycyclic aromatic hydrocarbons (PAHs) in aerobic bacteria suggests the involvement of a diversity of enzymes (Mahajan et al., 1994). These include oxidation of methyl group to alcohol, aldehyde, or carboxylic acid, decarboxylation, demethylation, and deoxygenating. However, PAHs and their alkyl derivatives can be transformed by various anaerobes through novel catabolic pathways (Annweiler et al., 2002; Zhang and Young, 1997). In comparison with aerobic bacteria initiating dioxygenation, anaerobic bacteria usually insert carboxyl groups from carbon dioxide or succinic acids (Mahajan et al., 1004). In our studies naphthalene transformation products in the extract of $60 \mathrm{ppm}$ naphthalene broth culture were detected through GC-MS and identified as Cholesta-4,6-dien-3-ol, Oleyl alcohol, acetic acid,2-dodecan-1-yl-succinic anhydride and fumaric acid (Figs. 5-7).

However, GC-MS of the $100 \mathrm{ppm}$ of naphthalene broth detected octadec-9-enoic acid and phthalic acid (Mrozik et al., 2003) the other transformation products of naphthalene. Acetic acid and fumaric acid as detected in $60 \mathrm{ppm}$ naphthalene broth were not detected in $100 \mathrm{ppm}$ broth. Mallick et al., (2007) reported that a novel meta-cleavage of 2-hydroxy-1-naphthoic acid to form trans-2, 3-dioxo-5- (2'-hydroxyphenyl)-pent-4-enoic acid in Staphylococcus sp. The ring fission product 4-(2-Hydroxyphenyl)-2-oxo-butenoic (2-hydroxybenzal pyruvic acid) and trans-2,3-dioxo-5-(2'-hydroxyphenyl)-pent-4enoic acid as reported by different authors were not detected in our studies with Nocardiopsis alba, however, another product octadec-9-enoic acid was identified. Phthalic acid, the transformation product of naphthalene detected in our study may arise from degradation of 2-carboxylcinnamic acid (Annweiler et al., 2000). However, 2carboxylcinnamic acid was not detected in our study; probably it has been instantly transformed to phthaic acid before extraction. Succinic acid the transformed product of naphthalene as reported by many authors (Rainer et al., 2004) was not detected in our study, however 2-dodecan-1-yl-succinic anhydride has been identified which is probably derived from unstable succinic acid in due course. Acetic acid and fumaric acid are the other derivative of naphthalene detected in our study similar to other authors (Annweiler et al., 2002; Meckenstock et al., 2004).

The occurrence of phthalic acid, acetic acid, fumaric acid, octadec-9-enoic acid and 2dodecan-1-yl-succinic anhydride strongly suggests that Nocardiopsis alba efficiently degrades naphthalene into its derivative products.

\section{Acknowledgement}

Authors are grateful to University Grant Commission for financial support to the corresponding author to carry out this research work.

\section{References}

Alexander, M.1999.Biodegradation and Bioremediation.2nd Ed.; Academic Press: San Diego, USA, pp. 325-327.

Annweiler, E., Materna, A.,Safinowski, M., Kappler, A., Richnow, H.H., Michaelis, W., and Meckenstock, R.U. (2000). Anaerobic degradation of 2-methylnaphthalene by a sulfate-reducing enrichment culture. Appl. Environ. Microbiol. 66, 5329-5333.

Annweiler, E.; Michaelis, W.; Meckenstock, R.U. Identical ring cleavage products during anaerobic degradation of naphthalene, 2methylnaphthalene, and tetralin indicate a new metabolic pathway. Appl. Environ. Microbiol.2002, 68, 852-858.

Esedafe, WK., Fagade, OE. Umaru, F.F. and Akinwotu, O. 2015. Bacterial Degradation of the Polycyclic Aromatic Hydrocarbon (PAH) - Fraction of Refinery Effluent. 
International Journal of Environmental Bioremediation and Biodegradation.3: 2327.

Gopinath, M. and Dhanasekar, R. 2012.Microbial degradation of toluene.AfricanJournal of Biotechnol. 11: 16210-16219

Kafilzadeh, F.; Rafiee S. and Tahery, Y. 2011. Evaluation of Bioremediation of naphthalene using native bacteria isolated from oil contaminated soils in Iran. Annals of Biological Research. 2: 610-616.

Latha, R. and Kalaivani, R. 2012.Bacterial Degradation of Crude Oil by Gravimetric Analysis. Advances in Applied Science Research. 3: 2789-2795.

Mahajan, M.C., Phale, P.S.; Vaidyanathan, C.S. 1994. Evidence for the involvement of multiple pathways in the biodegradation of 1 and 2-methylnaphthalene by Pseudomonas putida.CSV86.Arch. Microbiol. 161, 425-433.

Mallick S., Chatterjee S. andDutta T.K. (2007). A novel degradation pathway in the assimilation of phenanthrene by Staphylococcus sp. strain PN/Y via metacleavage of 2-hydroxy-1-naphthoic acid: formation of trans-2, 3-dioxo-5-(29 hydroxyphenyl)-pent-4-enoic acid.Microbiology.153, 2104-2115.

Mittal, A. and Singh, A. 2009. Isolation of Hydrocarbon degrading Bacteria from soil contaminated with crude oil spills. Indian Journal of Experimental Biology.47: 760765.

Mrozik, A.; Priotowska-Seget, Z. and Labuzek, S. 2003. Bacterial degradation and bioremediation of polycyclic aromatic Hydrocarbon (2003).Polish J. of Environ. Studies.12:15-25
Pawar, A.N.; Ugale S.S.; More M.G.; Kokani, N.F. and Khandelwal, S.R. 2013. Biological Degradation of Naphthalene: A New Era. $J$. Bioremed. Biodeg. 4:203.

Schlegel, H.G. 1986. Xenobiotics In: General Microbiology. 6th edition Cambridge University Press N.Y. pp. 433.

Singh R., Singh P. and Sharma, R.2014.Microorganism as a tool of bioremediation technology for cleaning environment: A review. Int. Academy of Ecol. Env. Sc. 4: 1-6.

Singh A. and Ward O.P. (Eds.). 2004. "Biodegradation and Bioremediation", Springer-Verlag Berlin Heidelberg. pp. 174.

Tanti B. and Buragohain A.K. 2013. Biodegradation of Petroleum Tar by Pseudomonas Spp. From Oil Field of Assam, India. Bioremediation Journal. 17: 107-112.

Thakur P.K. and Balomajumder C. 2012.Biodegradation of o-xylene by Azotobacter chroococcum. Int. J. of Adv.Biotechnol.and Res. 3: 502-508.

Varsha Y.M., C.H. Naga Deepthi and S. Chenna. 2011. An Emphasis on Xenobiotic Degradation in Environmental Cleanup. $J$ BioremedBiodegrad.11: 001.

Ward OP., Singh A. and Van, H. J. 2003.Accelerated biodegradation of petroleum hydrocarbon waste. J Industrial Microbial Biotechnol.30:260-270.

Zhang X.; Young L.Y. Carboxylation as an initial reaction in the anaerobic metabolism of naphthalene and phenanthrene by sulfidogenic consortia. Appl. Environ. Microbiol.1997, 63, 4759-4764.

\section{How to cite this article:}

Ruby Doley, Manoj Barthakur and Bijoy S. Goswami. 2017. Microbial Degradation of Aromatic Hydrocarbon: Naphthalene through Nocardiopsis alba RD3. Int.J.Curr.Microbiol.App.Sci. 6(7): 1174-1181. doi: https://doi.org/10.20546/ijcmas.2017.607.142 